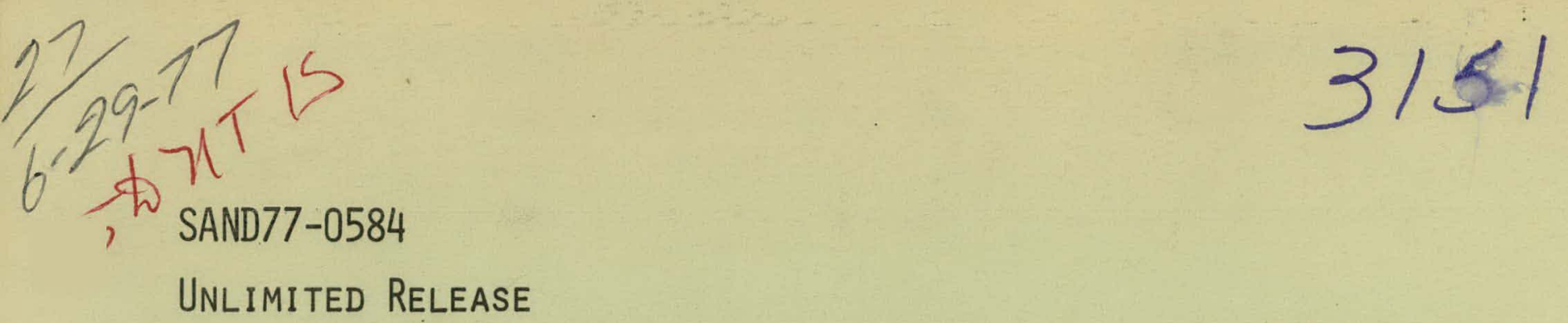

\title{
AN AUGER-ELECTRON LINE-SHAPE STUDY OF CVD SILICON NITRIDE FILMS
}

H, H, Madden, G, Moore, and P, H, Holloway

Prepared by Sandia Laboratories, Albuquerque, New Mexico 87115 and Livermore, California 94550 for the United States Atomic Energy Commission under Contract AT (29-1)-789

Printed May 1977

\section{Sandia Laboratories}




\section{DISCLAIMER}

This report was prepared as an account of work sponsored by an agency of the United States Government. Neither the United States Government nor any agency Thereof, nor any of their employees, makes any warranty, express or implied, or assumes any legal liability or responsibility for the accuracy, completeness, or usefulness of any information, apparatus, product, or process disclosed, or represents that its use would not infringe privately owned rights. Reference herein to any specific commercial product, process, or service by trade name, trademark, manufacturer, or otherwise does not necessarily constitute or imply its endorsement, recommendation, or favoring by the United States Government or any agency thereof. The views and opinions of authors expressed herein do not necessarily state or reflect those of the United States Government or any agency thereof. 


\section{DISCLAIMER}

Portions of this document may be illegible in electronic image products. Images are produced from the best available original document. 
Issued by Sandia Laboratories, operated for the United States Energy Research \& Development Administration by Sandia Corporation.

\section{NOTICE}

This report was prepared as an account of work sponsored by the United States Government. Neither the United States nor the United States Energy Research \& Development Administration, nor any of their employees, nor any of their contractors, subcontractors, or their employees, makes any warranty, express or implied, or assumes any legal liability or responsibility for the accuracy, completeness or usefulness of any information, apparatus, product or process disclosed, or represents that its use would not infringe privately owned rights.

Printed in the United States of America

Available from

National Technical Information Service

U. S. Department of Commerce

5285 Port Royal Road

Springfield, Virginia 22151

Price: Printed Copy $\$ 3.50 ;$ Microfische $\$ 3.00$ 
SAND77-0584

Unlimited Release

AN AUGER-ELECTRON LINE-SHAPE STUDY OF CVD SILICON NITRIDE FILMS

H. H. Madden, G. Moore* and P. H. Holloway

Sandia Laboratories, Albuquerque, New.Mexico 87115

May 1977

ABSTRACT

The shapes of integral Auger-electron signals from chemicalvapor-deposited silicon nitride with 0.3 atz and 12 atz oxygen have been compared with each other and with signals from clean $\mathrm{Si}$ and $\mathrm{SiO}_{2}$. The data show the probable existence of elementally bound $\mathrm{Si}$ in the nitrides. Incorporation of oxygen decreases the structure associated with elemental si but does not cause the $\mathrm{Si} \mathrm{L} 2,3 \mathrm{VV} 1$ ine shape to change to that characteristic of $\mathrm{SiO}_{2} \cdot$ The nitrogen peak shape was not affected by the increase in oxygen content to 12 atz, but the shape of the oxygen signal, and its energy location in silicon nitride is considerably different than for oxygen in $\mathrm{SiO}_{2}$. These data indicate that a detailed investigation of silicon nitride could lead to a better understanding of properties important to passivation and memory.

*Sandia Laboratories Summer Visitor, 1976. 


\section{TABLE OF :CONTENTS}

\section{Page}

INTRODUCTION

EXPERIMENTAL

RESULTS AND DISCUSSION

SUMMARY AND CONCLUSION

REFERENCES

FIGURE CAPTIONS

TABLE I

23

FIG. 1

24

FIG. 2

25

FIG. 3

26

FIG. 4

27 


\section{INTRODUCTION}

Since the invention of the transistor a variety of analytical techniques have been applied to study the surface properties of semiconductor devices. The initial problems concerning the structure of and contaminants on the surfaces of the early elephantine transistors have lead to a wide variety of surface investigations dealing with the structures of the highly sophisticated integrated-circuit components of today's electronics technology. Of great importance in this technology are the insulating, passivating and charge storage properties of thin films of silicon dioxide $\left(\mathrm{SiO}_{2}\right)$, and silicon nitride $\left(\mathrm{Si}_{3} \mathrm{~N}_{4}\right)$ and related mixtures of these compounds. An early review of the structural and electronic conduction properties of $\mathrm{SiO}_{2}$ films has been given by Revesz. ' A more recent review of the electronic structure of $\mathrm{SiO}_{2}$, both crystalline and amorphous; may be found in a paper by Pantelides and Harrison, ${ }^{2}$ in which they compare valence-band density of state (DOS) calculations with photoelectron emission (ultra-violet [UPS] and $x$-ray [XPS]) data, with soft-x-ray emission spectra and with optical and soft-x-ray absorption spectra ( $\mathrm{SXS}$ ) from $\mathrm{SiO}_{2}$ samples. Investigations of the properties of silicon nitride have not been as extensive nor as basic as those of the oxide. A review of the various nitride deposition techniques as well as of electronic and optical properties relevant to the analysis of deposited films is given. in a book by Milek. ${ }^{3}$ 
The use of Auger electron spectroscopy (AES) as a surface analytical technique began in 1967 with the work of Harris. 4 Since that beginning AES has become a standard technique in analyzing the properties of semiconductor surfaces. Most of this work has been concerned with "fingerprinting" in terms of cataloguing the shapes and energy shifts (chemical shifts) of the directly recorded; first-derivative AES signals according to the chemical environment of the Auger-electron-emitting atom. $5-7$ More recentiy, AES together with ion sputtering $8=10$ has been used in depth profiling silicon oxide and nitride films. Microscopic imaging using Auger electrons has also been found to be useful in the investigation of silicon integrated circuits. 11 In all these applications, the peak-to-peak "amplitudeș" of the derivative AES signals have been used as quantitative information on surface compositions and the energy positions of the negative peaks used to indicate chemical shifts. These uses of derivative signals are open to question however, 12 especially when the shape of the signal changes with chemical environmental.

Although AES has largely been used for elemental analysis of semiconductor-device materials, an Auger signal that involves the valence electrons has the potential of providing additional information on the valence band DOS. This information can supplement and enhance electronic analyses provided by other techniques such as UPS and XPS, especially. since the Auger transitions probe the local Dos around the site of the initial core vacancy. The first attempt to extract valence band information from a silicon AES signal was made in 1970 by Amelio. 13 
As directly, measured, integral AES data is generally distorted by loss-related features ${ }^{14}$ that present two problems in datareduction:. (1) the Auger signal is superimposed on a large secondary-electron background, uncorrelated to the Auger signal; that is rapidly varying; with energy, and (2) the Auger signal has a low energy tail caused by losses suffered by some of the Auger electrons while leaving the solid. Amel io apparently recognized such problems but did not properly correct his data for these loss-related features. Recently Houston, Moore and Lagally, 15 using a technique known as dynamic background subtraction 16 to handle the first problem and the van Cittert deconvolution technique 17 to handle the second, have obtained deconvoluted $\mathrm{L}_{1} \mathrm{~L}_{23} \mathrm{~V}$ and $\mathrm{L}_{23} \mathrm{VV}$. Auger spectra from sputtered and annealed (100) silicon surfaces with shapes that may be understood in terms of theoretical DOS calculations. Based on the simplest single-particle picture, the shape of the "true" LLV signal should be nearly the same as that of the valence band Dos while the shape of the LVV signal should closely approximate the self-fold of the valence band Dos.13,14 More detalled theoretical analysis of the silicui LVV signal 18 reveals that variations in the Auger transition probabilities across the band lead to a line shape that is largely duininated by the p-like states rather than the total Dos.

In this report deconvoluted AES data from two CVD silicon nitride films are presented. These two films differed in terms of the amounts of oxygen incorporated in the films - in the "good" film the AES oxygen level was near the detection limit of the experimental system while the oxygen level in the "poor" 
"poor" nịtride film was significantly greater. Besides the "fingerprinting" and chemical shift information, which may also be gleaned from uncorrected derivative data, the deconvoluted spectra provide easily assessed information on the widths of the valence bands and on increases (or decreases) in the relative DOS in various portions of the band. silicon $L_{23} \mathrm{VV}$, oxyyen $K L L$ and nftrogen $K L L$ spectra from these films are presented and compared with each other and with deconvoluted spectra from clean silicon ${ }^{15}$ and silicon dioxide. ${ }^{19}$

\section{EXPERIMENTAL}

The silicon nitride films (nominally $\mathrm{Si}_{3} \mathrm{~N}_{4}$ ) were deposited by chemical vapor deposition with conditions shown in Table 1 . The ammonia purity was $99.995+$ o while the nitrogen carrier gas was from a cyrogenic source with $\mathrm{H}_{2} \mathrm{O}$ (>20ppm), $0_{2}$ (86ppm) and $\mathrm{CO}_{2}$ (42ppm) impurities. The silane was semlconductor grade from Matheson Gas Products at $5 \%$ dilution in UHP. nitrogen.

An AMV 1200 CVD reactor, which is a cold-wall vertical type with a RF induction-heated graphite susceptor, was used for the deposition. Prior to insertion into the reactor, the n-doped silicon (111) wafers were cleaned with a sulfuric acid/peroxide mixture, scrubbed, then cleaned with a nitric acid/peroxide mixture. Our $\mathrm{SiO}_{2}$ sample was obtained by a similar cleaning followed by heating to $1000^{\circ} \mathrm{C}$ in air.

Auger electron data were taken with a scanning Auger electron spectrometer (Physical Electronics Industries). A $5 \mathrm{keV}, 1 \mu \mathrm{A}$ primary electron beam from a coaxial gun was used. The electron 
analyzer was a single stage cylindrical-mirror type and 2 volts P-P modulation was used to record the first derivative (dN(E)/dE) spectra. A 0.3 sec time constant with a $0.26 \mathrm{eV} / \mathrm{sec}$ sweep $\mathrm{r}$ ate was used. The samples were sputter cleaned prior to analysis with $500 \mathrm{eV}$ argon ions; the samples were not annealed prior to analysis. Index of refraction data were taken with a Gaertner Ll19 ellipsometer operating at a wavelength of $6328 \AA$.

The: data: reported below were taken from $\mathrm{Si}_{3} \mathrm{~N}_{4}$ films from depositions 134: and 13:., (Table 1). Although some data were taken on samples from depositions. 136 and 140, they will not be discussed here. $S \cdot i_{3} \mathrm{~N}_{4}$ from depositions 134 and 135 will be referred to as "good" and "poor" $\mathrm{Si}_{3} \mathrm{~N}_{4}$ films based upon their oxygen content $(0.3 \pm 0.2$ at and $12 . \pm 2$. at 8 , respectively). The oxygen content was determined by. the quantitative AES method described in Ref. 20 . The secondary-electron background in the $d N(E) / d E$ mode was very slowly varying so background subtraction was not a serious problem. For the high energy nitrogen and oxygen transitions only zero suppression based on the' average of the firct ten high energy points in the data file was used. The background varied sufficiently slowly in the region of the silicon signal that it could adequately be approximated as linear over the energy region of interest. . Thus a small linear background was subtracted from the silicon signals after zero suppression and before deconvolution. After background correction, an iterative deconvolution scheme was used to correct for the remaining loss-related distortions in the measured signal. Our application of this deconvolution technique involves the use of the near-elastic energy spectrum of backscattered 
electrons recorded when the sample surface is bombarded with a beam of monoenergetic electrons of energy equal to the threshold energy of the Auger signal. This spectrum is considered to be a good approximation to the system response function. Details of this deconvolution technique have been discussed in Ref. 21 .

\section{RESULTS AND DISCUSSION}

A series of uncorrected, derivative silicon $\mathrm{L}_{2}, 3 \mathrm{VV}$ spectra from clean si, silicon dioxide, ${ }^{19}$ and from our two nitride films is presented in Fig. 1. This is the form of the AES data that has been most frequently used in the past for "fingerprinting," for quantitative analysis, and for discussions of chemical shifts. It is clear from the shapes of these signals that large changes do occur with changes in the chemical environment of the silicon atom (or lon). What is not clear is which features are related to the structure of the valence band DOS and which are due to loss-related structures in the uncorrected integral spectra. The extent to which the widths of these derivative peaks are effected by instrumental broadening is also unclear.

Two $\mathrm{Si} / \mathrm{L}_{2}, 3 \mathrm{VV}$ spectra for $\mathrm{Sin}_{2}$ are given in Fig. 1 to illustrate a alanger to the experimentalist that exists in any AES or other investigation that involves electrons impinging on a solid surface. 22 The dashed curve in Fig. l was obtained from a $\mathrm{SiO}_{2}$ surface that had suffered appreciable electronbeam-stimulated dissociation. This resulted in the presence 
of elemental silicon on the surface. The high energy negative peak is therefore attributed to elemental surface silicon and not to silicon in $\mathrm{SiO}_{2}$. For the solid siö ${ }_{2}$ curve, Houston and Lagally 19 recorded the data with a background pressure of oxygen so that the effects of the electron-stimulated surface dissociation were offset by chemisorption of oxygen: The solid curve is considered to be more representative of $\mathrm{Si}$ in $\mathrm{SiO}_{2}$ than is the dashed curve. The Auger structure from $\mathrm{Si}_{3} \mathrm{~N}_{4}$ samples shown in Fig. 1 are seen to consist of a high energy peak with a shoulder on its low energy side. It has been suggested ${ }^{8}$ that the high-energy peak in this structure is the result of elemental silicon incorporated in the bulk of the nitride film during deposition. Exposure of such nitride samples to oxygen causes a reduction in the surface elemental si, presumably because of surface oxide formation. ${ }^{8}$ It is suggested therefore that $\mathrm{Si}_{\mathrm{i}}$ bound in $\mathrm{SiN}_{\mathrm{x}}$ is responsible for the low energy shoulder in the derivative spectra; when stoichiometry $\left(\mathrm{Si}_{3} \mathrm{~N}_{4}\right)$ is reached the energy of the negative peak should coincide with the energy of the shoulder ( $84 \mathrm{eV})$. Note that there is a fundamental difference between the elemental si found on nitride surfaces from that observed on oxide surfaces, although both can be reduced by exposure to oxygen. The surface elemental si on $\mathrm{SiO}_{2}$ is the result of electron-stimulated surface-reduction processes, and hence is produced by the measurement technique, while the elemental $\mathrm{Si}$ on the surface of the nitride is thought to be representative of a true non-stoichiometry in the bulk of the film. 
The deconvoluted silicon $\mathrm{L}_{2,3} \mathrm{VV}$ spectra from clean silicon, ${ }^{15,23}$ silicon dioxide, ${ }^{19,24}$ and our two nitride samples are given in Fig. 2. Differences between the nitride spectra and the $\mathrm{Si}$ and $\mathrm{SiO}_{2}$ spectra are rather clear-cut and it is obvious that these deconvoluted integral spectra can be used as "fingerprints" of the chemical states of $\mathrm{Si}$ on the surface. Comparing the widths of the spectra - a comparison that cannot be simply made for the uncorrected derivative spectra - shows that the "good" nitride structure is broader than either the $\mathrm{Si}$ or $\mathrm{SiO}_{2}$ results. Comparing the two nitride spectra one sees the peak of the "good" nitride occurs closer to the top of the valence band than does the peak for the "poor" nitride. Also, the signal distribution relative to the peak is weighted some what more toward higher energies for the "good" than for the "poor" nitride, although the high-energy thresholds for the two signal approximately coincide. These differences are consistent with the arguments that the "good" nitride has appreciable elemental silicon on its surface while the "poor" nitride has less, presumably due to bonding to the excess oxygen incorporated in the film. Finally, the width of the "poor" nitride signal is less than that of the "good" - and is close to the width of the $\mathrm{SiO}_{2}$ peak. However, even at 12 at oxygen in the "poor" nitride film, one cannot see the characteristic $\mathrm{SiO}_{2}$ shape in the "poor" nitride signal. Transmission electron diffraction results ${ }^{25}$ indicate that silicon dioxide and silicon nitride form a continuous series of solid solutions (silicon-oxynitrides) rather than simple mixtures (conglomerate structures). AES studies of the silicon, oxygen 
and nitrogen"signals from this system could aid in understanding the atomic and electronic properties of these materials.

The oxygen KLL spectrum from the "poor" nitride film is compared with the oxygen KLL spectrum from our $\mathrm{SiO}_{2}$ sample in Fig. 3. The most obvious differences between these two spectra are a chemical shift of some $4 \mathrm{eV}$ and the narrowness of the peaks in the signal from the nitride. These differences both indicate that the oxygen in the nitride film is chemically bound in a different configuration than the oxygen in $\mathrm{SiO}_{2}$. In addition, the narrowness of the peaks in the nitride spectrum suggests that the oxygen in this film is less strongly bound to its neighbors than is the oxygen in $\mathrm{SiO}_{2}$. Gas-phase Auger spectra is characterized by sharper features than those found in Auger spectra from solids. This is presumably due to the stronger binding between elements in solids. Also shown in Fig. 3 are the nitrogen KLL spectra from the two nitride films. These two spectra are practically identical indicating that the chemical environment of the nitrogen in the two films is the same.

The $\mathrm{L}_{2,3} \mathrm{VV}$ silicon signal from the "good". nitride is some 52-54 eV wide at its base which, on the basis of the simplest arguments ${ }^{13,14}$ relating the width of a core-valence-valence AES signal to twice the valence-band width, indicates a valence band width in the nitride of $26-27 \mathrm{eV}$. The valence-band width for the clean silicon, based on the same arguments concerning the width of the $\mathrm{L}_{2}, 3 \mathrm{VV}$ signal, is only $\sim 10 \mathrm{eV}$. These values may be compared with values of $\sim 15$ eV for silicon and $\sim 18$ eV for silicon carbide from Sxs measurements. 26 
Based upon reports in the literature and the present data, it is likely that the present nitride films are substoichiometric (where $\mathrm{Si}_{3} \mathrm{~N}_{4}$ is generally considered stoichiometric) in nitrogen. The high energy nitride-spectra peaks in Figs. 1 and 2 probably represent $\mathrm{Si}$ bound in a more elemental configuration. As oxygen concentration in the nitride increases, the elemental $\mathrm{Si}$ peak narrows and shifts in energy toward that of $\mathrm{Si}$ in $\mathrm{SiO}_{2}$. However, the characteristic $\mathrm{L}_{2,3} \mathrm{VV}$ structure for $\mathrm{SiO}_{2}$ (shown in Fig. 2) never appears, even at 12 at oxygen ("poor" nitride), therefore it seems unlikely that oxygen converts the elemental $\mathrm{Si}$ in the nitride films to $\mathrm{SiO}_{2}$. Rather, it is more likely that an oxynitride is formed, ${ }^{25}$ as evidenced by the differences between the oxygen peaks from the "poor" nitride and from $\mathrm{SiO}_{2}$. The exact effect of these changes on the passivating and memory properties of the nitride are unknown. While elimination of of the elemental silicon from the nitride films may be desirable from a passivation point-of-view, it may be undesirable for a memory application.

The bonding in $\mathrm{SiO}_{2}$ is thought to have appreciable ionic character with the effective charge on the oxygen anion being some 1.02 electron charges. ${ }^{2}$ This means that the valence electrons are largely localized on the anion sites, and such compounds offer cases for which the ideas of interatomic (or crossover) transitions 27,28 may be tested. Indeed, soft $x-r a y$ spectroscopic (SXS) studies of $\mathrm{SiO}_{2}$ show evidence of crossover transitions from both the oxygen $2 p$ and $2 s$ levels in the 
silicon $\mathrm{L}_{2}, 3^{\text {-emission spectrum }}{ }^{26}$ and in the $\mathrm{L}_{3}$ absorption spectrum: ${ }^{29}$. According to the interatomic interpretation in sxs the $3 \mathrm{~s}$ and $3 p$ :levels of the silicon ion in $\mathrm{siO}_{2}$ lie well above the Fermi level and thus the only valence electrons available for a transition to fill an L-shell hole on the silicon ion would be those in the oxygen $L$ shell. On this basis, the cation and anion:soft $x$-ray spectra are expected to have, and have been roughly shown to have 26,29 the same width, if not identical shapes. The $: \mathrm{L}_{2}, 3 \mathrm{VV}$ Auger process involves two holes in the valence band while that for the related soft $x-r a y$ emission process involves only a single hole. If hole-hole interactions can be ignored, simple interatomic transition arguments. based on a common valence band and the different core hole states for the silicon and oxygen ions would predict that the $\mathrm{L}_{2}, 3 \mathrm{VV}$ silicon (assuming the $\mathrm{L}_{2}-\mathrm{L}_{3}$ splitting is negligible) and the $\mathrm{kVV}$ oxygen signals.should have the same width and this width should be "twice that of the valence band.

In Fig. 4, the deconvoluted $\mathrm{KVV}$ oxygen spectrum from $\mathrm{SiO}_{2}$ has been plotted along with the $\mathrm{L}_{2,3} \mathrm{VV}$ silicon spectrum from the same sample. ${ }^{19}$ The oxygen spectrum has been shifted so that its peak, which actually occurs at $496 \mathrm{eV}$ in the HoustonLagally data, ${ }^{19}$ is aligned with the major peak of the silicon spectrum. The low-energy oxygen Auger features involve the $2 \mathrm{~s}$ (non-valence-band) electrons. It is obvious from this comparison that the oxygen and silicon valence band spectra have somewhat 
similar widths. There are also some similarities in the shapes of the two curves. Even on strict interatomic-transition argument, differences in the shapes of the two signals would be expected since the relative magnitudes of the transition matrix elements for the two Auger transitions.will probably differ. One may further expect that, since the ionicity of $\mathrm{SiO}_{2}$ is probably not as great as ionic compounds such as the alkali halities, the silicon transition is not strictly interatomic but that the transition samples some valence electron distribution in the vicinity of the silicon ion.

Although one might suspect ${ }^{30}$ that $\mathrm{Si}_{3} \mathrm{~N}_{4}$ is less ionic than $\mathrm{SiO}_{2}$, a comparison of the nitrogen $\mathrm{KVV}$ and silicon $\mathrm{L}_{2,3} \mathrm{VV}$ spectra from our "good" nitride, Fig. 4, reveals a close agreement in signal widths. The structure at the low end of the nitrogen spectrum is probably due to the non-valence-band 2 s electrons, but this structure may be superimposed on the low energy tail. of the KVV signal. The shapes of the two signals are quite different from one another if the low energy peaks are considered part of the nitrogen $\mathrm{KVV}$ structure. It is interesting to note that a similar comparison of the nitrogen and silicon spectra for the "poor" nitride, as noted above, shows quite a difference in cignal widths. The "pour"nitrlae gilicon signal is cluser in width to the silicon signal from $\mathrm{SiO}_{2}$ than to the $\mathrm{Si}$ signal from the "good" nitride. This illustrates the local nature of AES as a DOS probe, i.e., the valence electrons "viewed" by the 
silicon core in the "poor" nitride are different from those

"viewed" by the nitrogen core, and iliustrates one of the principal advantages of a "core-level" probe such as AES for studying surface electronic properties.

\section{SUMMARY AND CONCLUSION :}

A preliminary investigation has been conducted into the shapes and widths of $\mathrm{N}(\mathrm{E})$ Auger electron signals from silicon nitride. Silicon, oxygen and nitrogen Auger peaks from nitrides with either 0.3 atz or 12 at oxygen were compared to Auger peaks from pure Si or $\mathrm{SiO}_{2}$. The purpose of this study was to determine whether peak-shape analysis shows promise of aiding future improvements in the passivating and memory properties of nitride films. Such improvements seem logical since the present data show probable existence of elementally bound silicon in the nitrides. As the oxygen concentration increased to 12 atz, the elementally bound $\mathrm{Si}$ decreased in concentration while the silicon peak energy shifted, and the 1 ine width decreased, toward that of $\mathrm{SiO}_{2}$. The $^{\circ}$ nitrogen peak energy and shape did not change with the increase in oxygen concentration, but the oxygen peak from the nitride was significantly different in energy and shape than that from oxygen in $\mathrm{SiO}_{2}$. Thus, up to 12 ats, oxygen in silicon nitride is most 1 ikely accommodated in an oxynitride structure rather than in an $\mathrm{SiO}_{2}$ configuration. It seems reasonable to speculate that this type of analysis could also reveal the effects of incorporating other elements in nitrides (e.g. hydrogen). 
Although the application of AES to detailed studies of surface electronic properties is presently in a rather primitive state, it seems clear from work such as outlined here that considerable additional "chemical-state" information is contained in the line shapes and that this information could be invaluable aid in future work relating process variables and the passivating and memory properties of nitride films. 


\section{REFERENCEŚ}

1. A. G. Revesz, Phys. Stat. Solidi 24, 115 (1967).

2. S. T. Pantelides and W. A. Harrison, Phys. Rev. B13, $2667(1976)$.

3. J. T. Milek, Handbook of Electronic Materials, Vol. 3, Pt. I (J. F. I. Plenum Data Corp., New York, 1971).

4. L. A. Harris, J. Appl. Phys. 39, 1419 (1968).

5. G. W. Stupian, J. Appl. Phys. 45, 5278 (1974).

6. H. G. Maguire and P. D. Augustus, J. Electrochem. Soc.: Solid-State Sci. Technol. 119, 791 (1972).

7. J. S. Johannessen, W. E. Spicer and Y. E. Strausser, Farad. Discuss. $60,(1976)$ (in press).

8. Y. E. Stausser and J. S. Johannessen, NBS Special Publ. 400-23, ARPA/NBS Workshop IV, Surface Analysis for Silicon Devices, A. G. Lieberman, ed., (March 1976), p. 125.

9. J. S. Johànessen, W. E. Spicer and Y. E. Strausser, NBS Spec. Publ. 400-23, ARPA/NBS Workshop IV, Surface Analysis for Silicon Devices, A. G. Lieberman, ed., (March 1976), p. 119 .

10. J. S. Johannessen, W. E. Spicer and Y. E. Strausser, Thin Solid Films, 32, 311 (1976).

11. J. M. Morabito, NBS Spec. Publ. 400-23, ARPA/NBS Workshop IV, Surface Analysis for Silicon Devices, A. G. Lieberman, ed. (March 1976), p. 105 .

12. See comments by N.E. Erickson following paper of Ref. 8 (page 137). 
13. G. F. Amelio, Surf. Sci. 22, 201 (1970).

14. J. J. Lander, Phys. Rev. 91, 138 (1953).

15. J. E. Houston, G, Moore and M. G. Lagally, Solid State Commun. 21, 879 (1977).

16. J. E. Houston, Rev. Sci. Instrum. 45, 897 (1974).

17. J. E. Houston, J. Vac. Sci. Technol. 12, 255 (1975).

18. P. J. Feibelman, E. J. McGuire and K. C. Pandey, Phys. Rev. Lett. 366, 1154 (1976); Phys. Rev. B (in press).

19. J. E. Houston and M. G. Lagally, unpublished results.

20. P. H. Holloway and H. J. Stein, J. Electrochem. Soc.: Solid State Sci. Technol. 123, 723 (1976).

21. H. H. Madden and J. E. Houston, J. Appl. Phys. 47, 3071 (1976).

22. H. H. Madden, J. Vac. Sci. Technol. 13, 228 (1976).

23. The deconvoluted clean silicon spectrum in Fig. 2 is not derived from the uncorrected clean silicon spectrum of Fig. 1. The companion backscatter spectrum - needed for deconvolution - was found to be seriously distorted when we set about deconvoluting the clean si data. This diotortion was nol evident in the raw derivaelve dáta. The source of the distortion is not clear although it may be related to the fact that the clean $\mathrm{Si}$ data was recorded while the sample was being sputtered. Possible ion-bombardment-induced distortions to the data could be very important in the analysis of ion-sputtering depth-profiling experiments and this possibility should be investigated further. 
24. Only the oxygen KLL spectra was recorded from our $\mathrm{SiO}_{2}$ sample.

25. W. C. Tombs, F. A. Sewell, Jr., and J. J. Comer, J. Electrochem. Soc.: Solid State Sci. Technol. 116, 862 (1969).

26. G. Wiech, "Soft X-Ray Emission Spectra and the Valence-Band

$\therefore$ structure of Beryilium, Aluminum, silicon and some silicon Compounds" in Soft X-Ray Band Spectra and the Electronic Structure of Metals and Materials, "P. J. Fabian, ed. (Academic Press, New York, 1968), p. 59

27. T.,E. Gallon and J.A. D. Matthew, Phys. Stat. Solidi 4l, $3.43 \%(1970) ;$ J., A. D. Matthew and Y. Komninos, Surf. Sci. 53, 716 (1975).

28. P. H. Citrin, J. Electron Spectrosc. Relat. Phenom. $\underline{5}$, $273(1974)$.

29. H. M. O'Bryan and H. W. B. Skinner, Proc. R. Soc. London, Ser. A 176, 229 (1940).

30. We know of no direct experimental or theoretical investigations dealing with the ionicity of $\mathrm{Si}_{3} \mathrm{~N}_{4} \cdot$ 


\section{FIGURE CAPTIONS}

FIG. 1 Uncorrected Derivative Silicon $\mathrm{L}_{2,3}$ VV AES Spectra from clean silicon, $\mathrm{SiO}_{2}$ and Two Silicon Nitride Films.

FIG. 2 Integral Silicon $\mathrm{L}_{2,3}$ VV AES Spectra After Deconvolution from Clean silicon, $\mathrm{SiO}_{2}$ and Two silicon Nitride Films.

FIG. 3 Comparison of Integral Oxygen and Nitrogen KLL AES Spectra After Deconvolution from $\mathrm{SiO}_{2}$ and Two Silicon Nitride Films.

FIG. 4 Comparison of Integral "Cation" and Anion" AES Spectra After Deconvolution from $\mathrm{SiO}_{2}$ and $\mathrm{Si}_{3} \mathrm{~N}_{4}$. 
TABLE 1 - CONDITIONS FOR DEPOSITING $\mathrm{SI}_{3} \mathrm{~N}_{4}$ FILMS

\begin{tabular}{|c|c|c|c|c|c|c|}
\hline $\begin{array}{l}\text { Deposition } \\
\text { Number }\end{array}$ & Tempgrature & $\begin{array}{c}\text { Ammonia/ } \\
\text { Silane }\end{array}$ & $\begin{array}{l}\text { Silane } \\
\text { Flow } \\
\text { (cc/min) }\end{array}$ & $\begin{array}{c}\text {-Total } \\
\text { Flow } \\
\text { (1/min) }\end{array}$ & $\begin{array}{c}\text { Thickness } \\
\left({ }_{A}\right)\end{array}$ & $\begin{array}{l}\text { Index of } \\
\text { Refraction }\end{array}$ \\
\hline 134 & 900 & $300: 1$ & 5 & 58 & 750 & 1.94 \\
\hline 135 & 800 & $300: 1$ & 5 & 58 & 600 & 1.75 \\
\hline 136 & 750 & $300: 1$ & 11 & 58 & 670 & 1.82 \\
\hline 140 & 700 & $300: 1$ & 50 & 58 & 720 & 1.82 \\
\hline
\end{tabular}




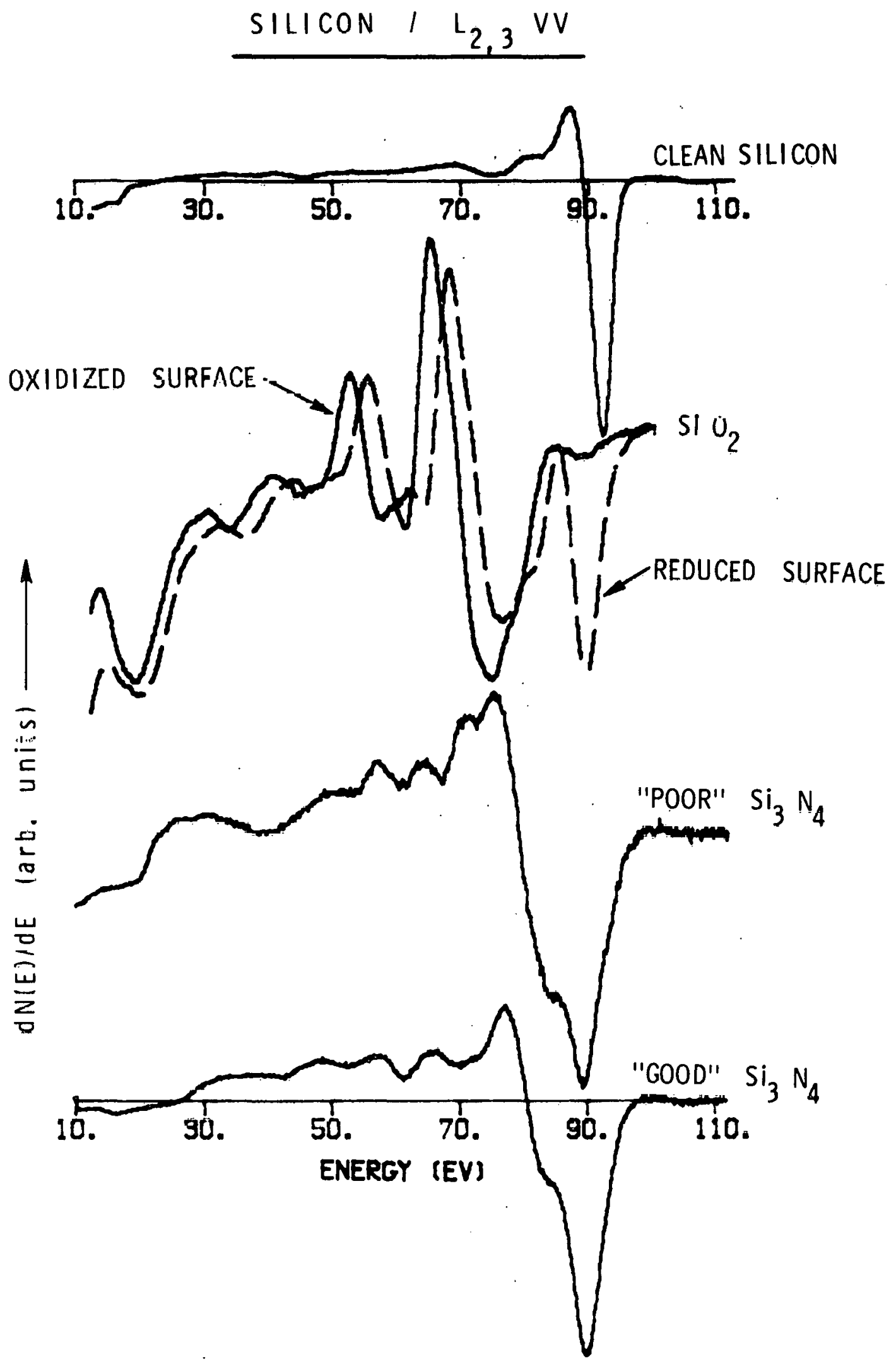

FIG. 1 
DECONVOLUTED SILICON $\mathrm{L}_{2,3} \mathrm{VV}$

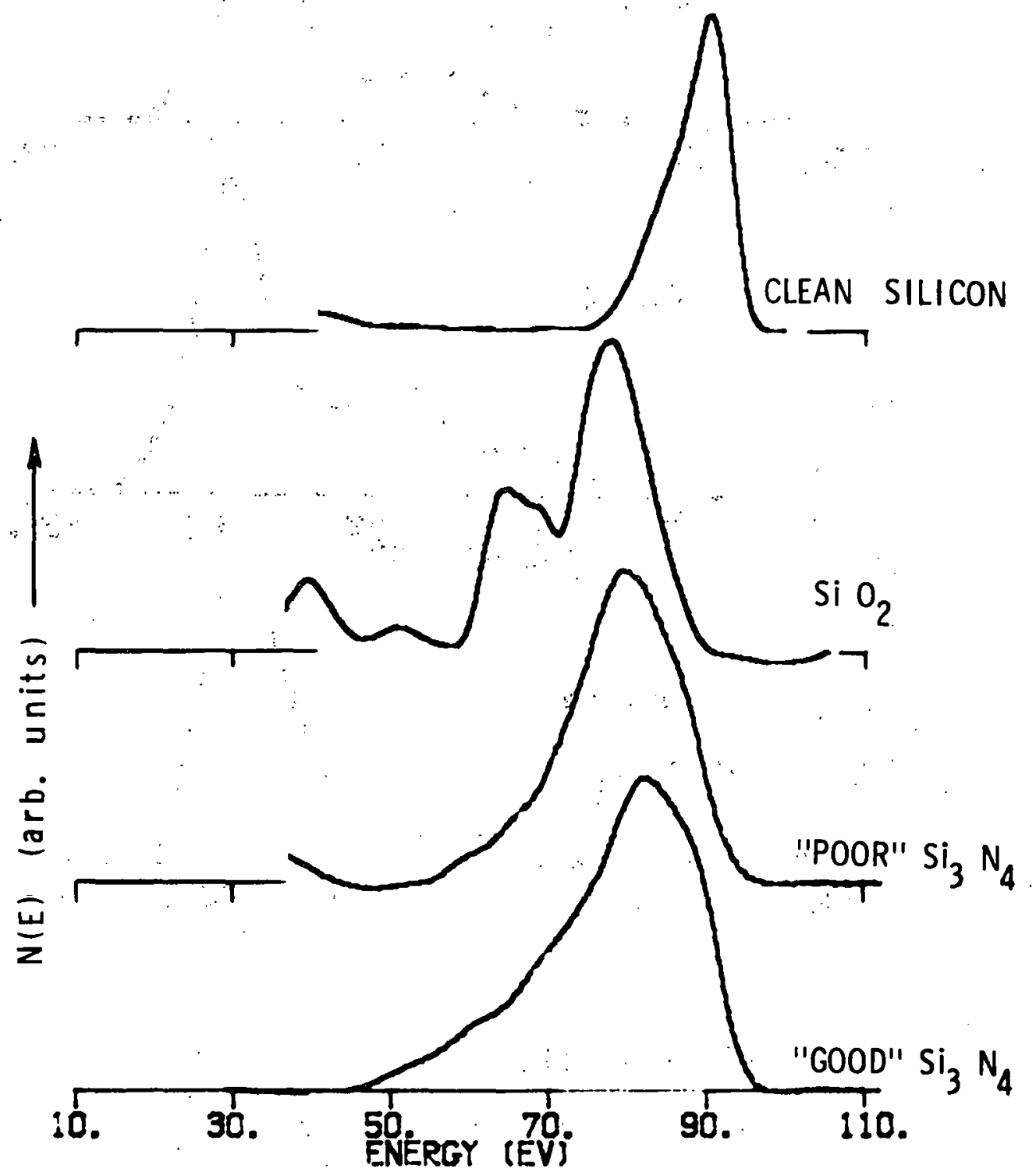

FIG. 2

25 


\section{COMPARISON OF OXYGEN AND NITROGEN KLL SPECTRA}

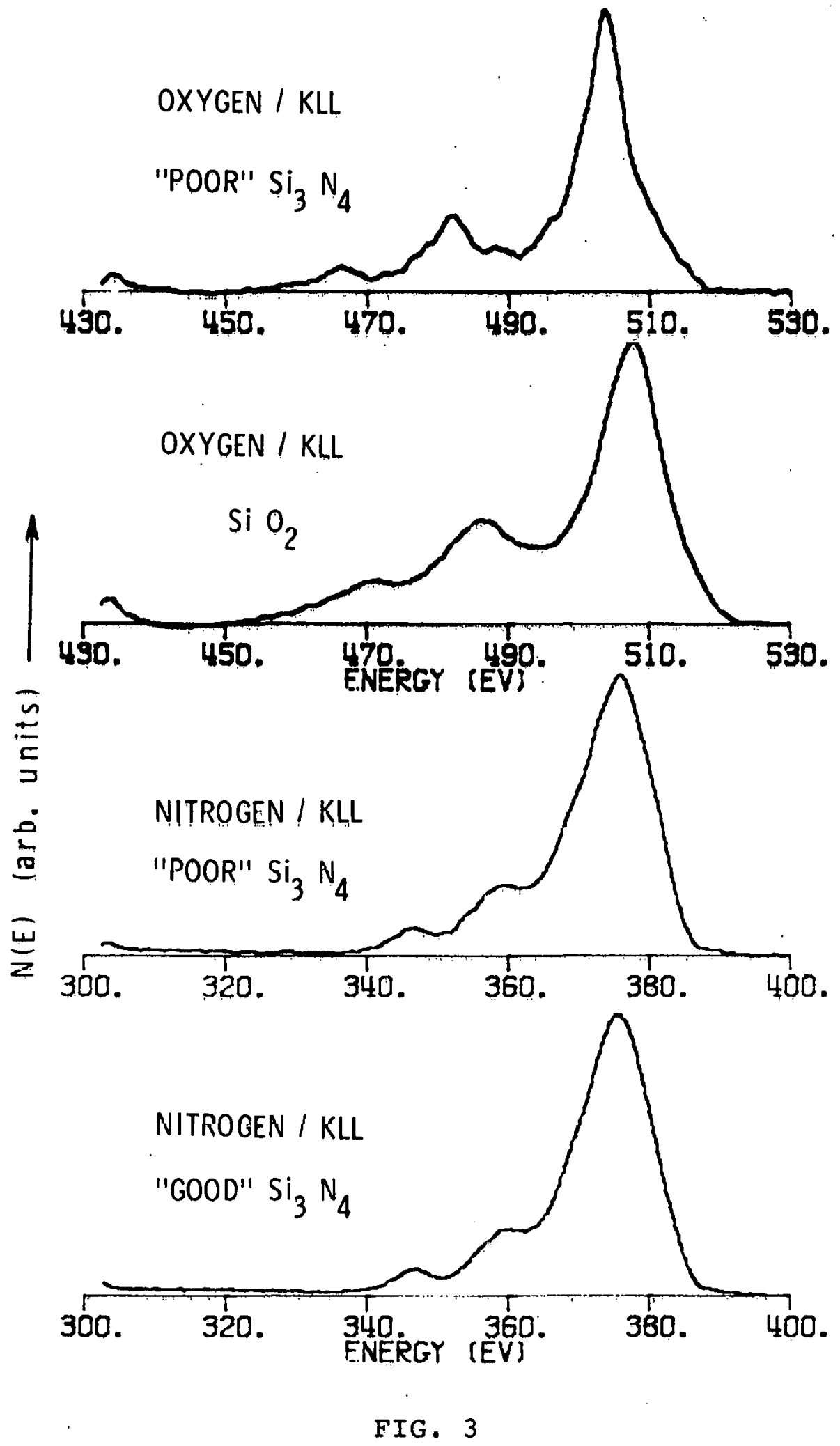




\section{COMPARISON OF "CATION" AND "ANION" AES SPECTRA FROM

$\mathrm{Si}_{2}$ AND $\mathrm{Si}_{3} \cdot \mathrm{N}_{4}$

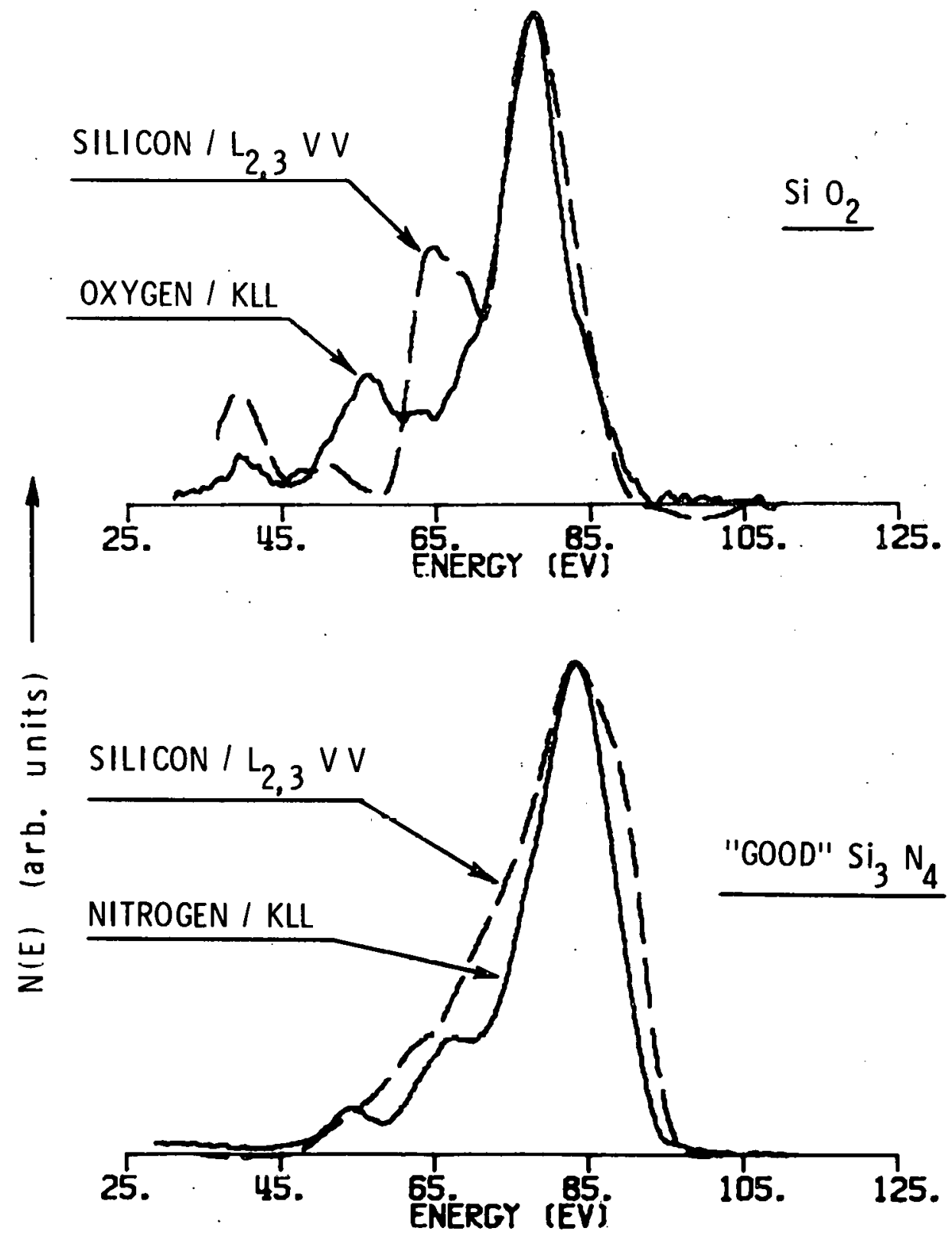

FIG. 4 


\section{DISTRIBUTION :}

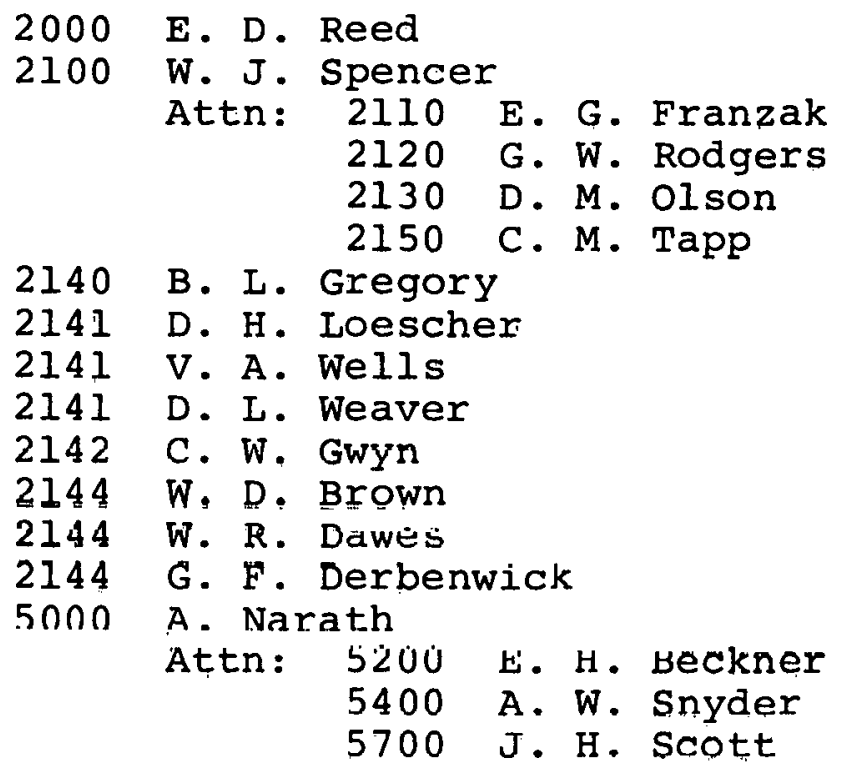

5820 R. I. Schwoebel

Attn: 5822 R. E. Whan 5824 R. W. Lynch

5821 J. C. Russell

5825 A. W. Mullendore

5825 P. H. Holloway (10)

5830 M. J. Davis

$5833 \mathrm{~J}$. L. Ledman

5834 G. J. Kominiak

3141 C. A. Pepmueller (actg.) (5)

8266 F. A. Aas (2)

3151 W. L. Garner (3)

For: ERDA/TIC (Unlimited Release)

ERDA/TIC (25)

(R. P. Campbel1, 3171-1) 